\title{
EFFECTS ON ELLIPSOMETRIC PARAMETERS CAUSED BY HEAT TREATMENT OF SILICON (111) SURFACE
}

\author{
S. KONO *, L.J. HANEKAMP and A. VAN SILFHOUT \\ Department of Applied Physics, Twente University of Technology, Enschede, The Netherlands
}

Received 22 December 1976; manuscript received in final form 27 January 1977

Heating of a silicon single crystal introduces a surface roughness. Crystals are heated for periods of $45 \mathrm{sec}$ in the temperature range from 560 to $1150^{\circ} \mathrm{C}$. Using ellipsometry, Auger electron spectroscopy, mass spectroscopy and micrography it has been shown that the changes in the ellipsometric parameters are caused by surface roughness which in turn is strongly related to the sublimation of silicon during heating. The relation between surface roughness and temperature of the crystal during the heating is not linear.

\section{Introduction}

Direct heating is extensively applied for the cleaning of silicon single crystal wafers. However, prolonged direct heating in vacuo $\left(\sim 10^{-10}\right.$ Torr $)$ at temperatures higher than $\sim 900^{\circ} \mathrm{C}$ may lead to difficulties. This was revealed by ellipsometry [1]. Sometimes it was observed that the ellipsometric parameters $\Delta$ and $\psi$ changed in an irreversible way after direct heating. Ibrahim et al. [1] suggested that the decrease in $\Delta$ might be caused by an increase in the surface contamination layer. Recently Hopper et al. [2] suggested that the changes in $\Delta$ and $\psi$ were caused by surface roughness. The critical heating temperature at which this surface roughness occurred was $900^{\circ} \mathrm{C}$ for silicon (111) and (100) surfaces. The present report will show that the changes in $\Delta$ and $\psi$ are caused by surface roughness which in turn is strongly related to the sublimation of silicon during heating. Ellipsometry, Auger electron spectroscopy, mass spectroscopy and micrography are used to this purpose.

\section{Experimental}

A silicon (111) wafer $\left(19 \times 8 \times 0.25 \mathrm{~mm}^{3}\right)$, prepared from a single crystal, dopant concentration $(60 \pm 20) \times 10^{14} \mathrm{~B}$ atoms per $\mathrm{cm}^{3}$, resistivity $20-50 \Omega \mathrm{cm}$,

\footnotetext{
* Research-fellow at Twente University of Technology. Present address: Department of Chemistry, University of Hawai, 2545 The Mall, Honolulu, 96822, USA.
} 
was polished with a suspensive of $\mathrm{SiO}_{2}$ particles (diameter $\sim 0.5 \mu \mathrm{m}$ ) in an aqueous solution of $\mathrm{KOH}$. The sample was clamped with two tantalum strips to a sample holder, which was attached to a manipulator. By means of this manipulator the sample could be moved in a translational and rotational manner at background pressure of $5 \times 10^{-10}$ Torr, so that the measurements of ellipsometry, Auger electron spectroscopy, mass spectroscopy and temperature of the sample were possible in situ. The ellipsometer was a home-made one with a resolution of the polarizers of $0.005^{\circ}$. The angle of incidence was $70.00^{\circ} \pm 0.02^{\circ}$ and the wavelength $6328 \AA$ (He-Ne laser light). The correction for pyrex glass windows was carried out according to Azzam et al. [3] by measuring $\Delta$ and $\psi$ at $1 \mathrm{~atm}$ with and without the windows at the final stage of the experiment. A hemicylindrical mirror Auger electron spectrometer (V.G. 850) was used. Ellipsometry and Auger electron spectroscopy could be carried out in the same sample position. In order to minimize electron induced adsorption of residual gases during the operation of the Auger electron spectrometer, an electron gun (V.G. 301) was operated at $3 \mathrm{kV}$ and $1 \mu \mathrm{A}$, which was checked. This was found to have no significant effect on the surface. The temperature was measured with a pyrometer (IRCON, T5C) using an emittance value of 0.64 (this value contains the correction for the pyrex window reflectance: $\sim 8 \%$ ). As for mass spectroscopy, two sample positions, with respect to a quadrupole mass spectrometer (RIBER, QMM 16), were applied in order to distinguish between nonvolatile gases originating in the sample and volatile gases originating in the sample or elsewhere. The two positions are (1), a sample position which is on the axis of the quadrupole mass spectrometer at a distance of $\sim 5 \mathrm{~cm}$ and (2), a sample position which is perpendicular to the axis of the spectrometer.

\section{Results}

Fig. 1 shows the effects of heating on $\Delta$ and $\psi$ as functions of time and temperature of heating. Measurements for $\Delta$ and $\psi$ were carried out at room temperature after heating periods of 45 seconds. The heating temperature was changed stepwise between 560 and $1080^{\circ} \mathrm{C}$, as is indicated in the figure. General trends of $\Delta$ and $\psi$ upon heating from 560 up to $870^{\circ} \mathrm{C}$ ( 8 heating periods) are gradual increases from $\sim 172^{\circ}$ to $\sim 175.5^{\circ}$ and from $10.65^{\circ}$ to $10.8^{\circ}$ respectively. After the next 7 heating periods at 975 and $1080^{\circ} \mathrm{C}, \Delta$ shows a slow decrease, whereas $\psi$ continues to increase. At $1080^{\circ} \mathrm{C}$ during 3 heating periods both $\Delta$ and $\psi$ show drastic decreases. Subsequent heating at 870 and $975^{\circ} \mathrm{C}$ did not result in any substantial change of $\Delta$ and $\psi$. Subsequent heating periods at $1080^{\circ} \mathrm{C}$ again caused a fairly strong decrease of $\Delta$ and $\psi$.

As many as 4 monolayers of carbon and 1 monolayer of oxygen are roughly estimated to exist on the sample surface prior to heating by Auger electron spectra [4]. After heating at $870^{\circ} \mathrm{C}$ (the 6th period) the Auger electron spectra showed splitting in the silicon LMM peak, indicating the existence of pure silicon, and the 


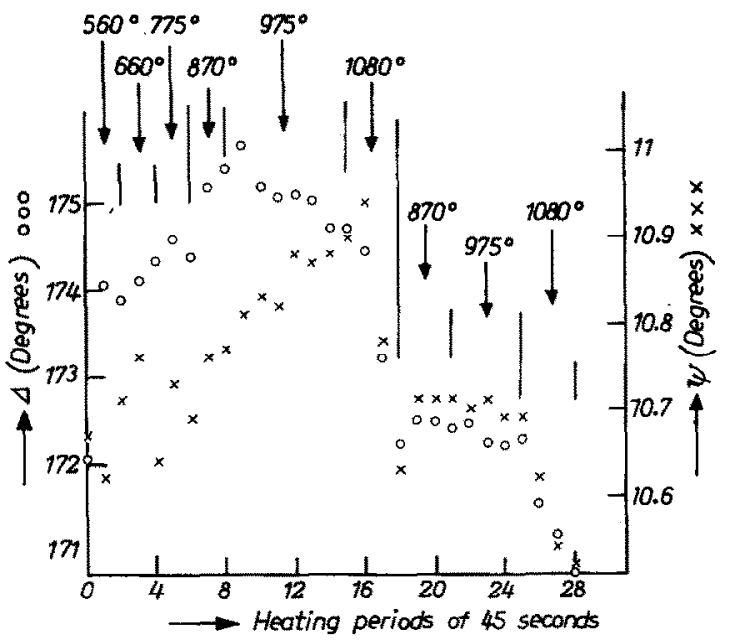

Fig. 1. Effects of heating on $\Delta$ and $\psi$ for the Si(111) surface. The measurements are carried out at room temperature after heating periods of $45 \mathrm{sec}$. The heating temperatures are indicated at the top of the figure and the heating periods are indicated on the abscissa.

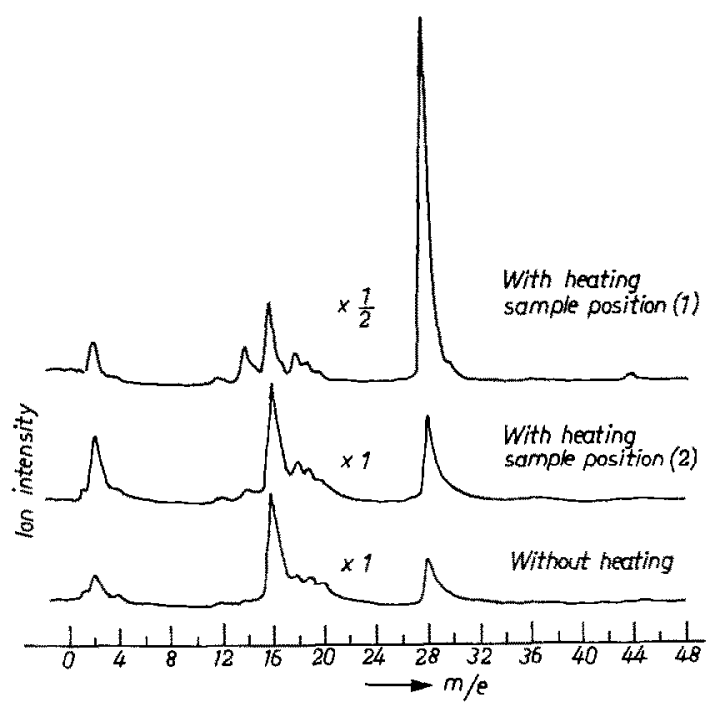

Fig. 2. Quadrupole mass spectra of the vacuum system with and without heating of the silicon (111) surface at temperature of $1100^{\circ} \mathrm{C}$ in sample positions (1) and (2). The energy of the ionizing electron is $70 \mathrm{eV}$. 

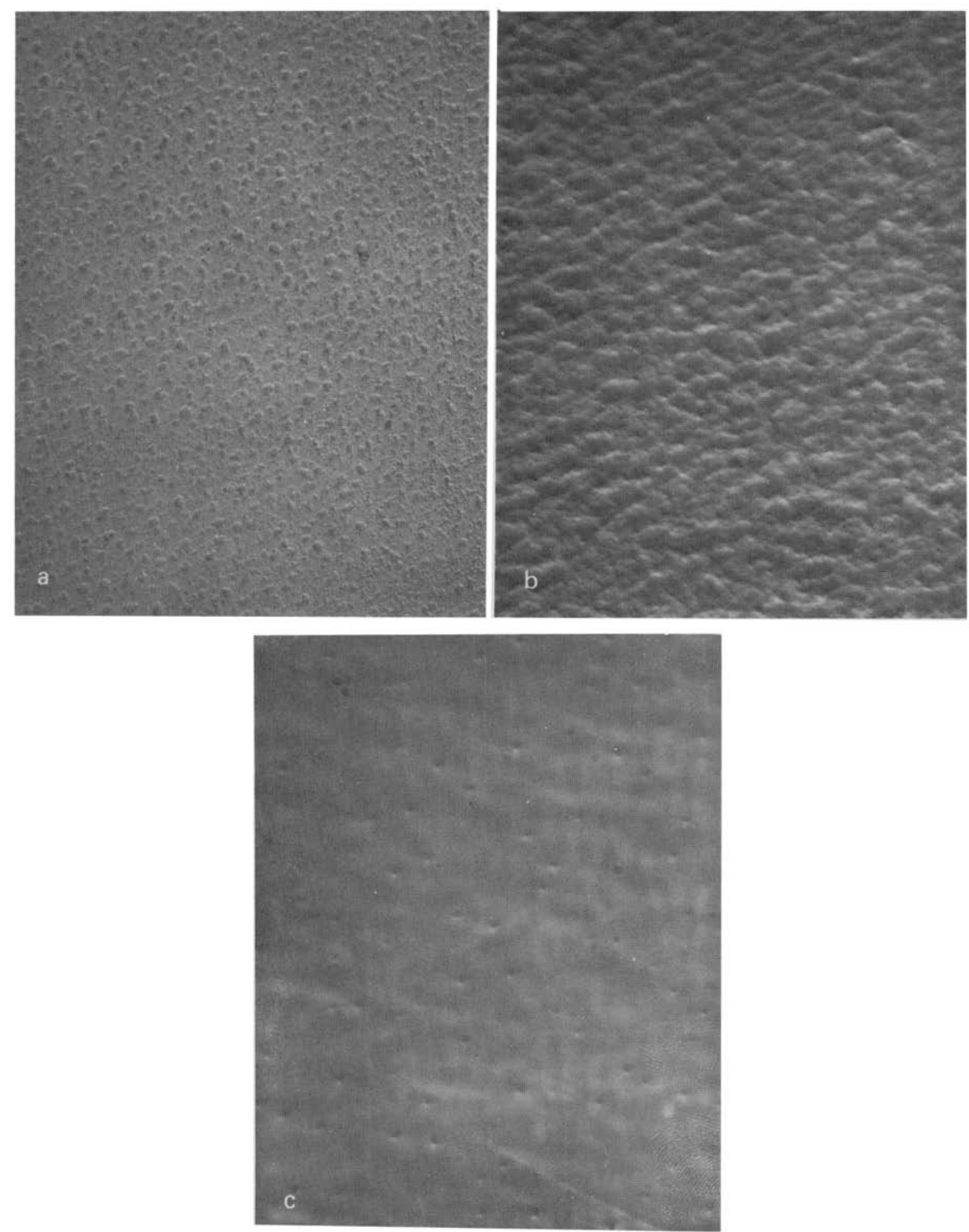

Fig. 3. Micrographs of the silicon (111) surface heated at several temperatures from $560^{\circ} \mathrm{C}$ to near the melting point of silicon for about $50 \mathrm{~min}$ in total.

probable presence of silicon oxides [5]. The Auger electron spectra measured after heating at $975^{\circ} \mathrm{C}$ (the 10 th period) showed a clear silicon LMM signal, the peak position of which was different from that of the previous silicon compounds. No carbon or oxygen was detected. The detection limits in this case are estimated [4] 
to be 0.04 and 0.006 monolayers for carbon and oxygen respectively. After heating at $1080^{\circ} \mathrm{C}$ (the 17 th period), in which $\Delta$ and $\psi$ showed a drastic decrease, the Auger electron spectra showed no sign of impurities in the Auger electron energy range from 100 to $900 \mathrm{eV}$. This range covers light metals and $3 \mathrm{~d}$ transition metals as well as carbon, nitrogen and oxygen.

Quadrupole mass spectra were measured several times during the heating periods referred to in fig. 1 and during heating periods at higher temperatures up to $1150^{\circ} \mathrm{C}$, carried out after the 28 th heating period. During the heating up to the 15 th period at $975^{\circ} \mathrm{C}$ there was a 20 -fold increase of the $\mathrm{H}_{2}^{+}$peak compared to that obtained at room temperature; the peaks at mass numbers $12,14,16,18$ and 28 increased slightly, at most by a factor of 2 . Changes in mass spectra for different sample positions were not detected in these cases. During heating at $1080^{\circ} \mathrm{C}(16 \mathrm{th}$ to 18 th period) the peak at mass number 28 was strongly increased by switching the sample from position (2) to position (1), whereas the $\mathrm{H}_{2}^{+}$peak was considerably reduced in both sample positions. The difference in peak height at mass number 28 in different sample positions became outstanding at higher heating temperatures. A demonstrative example of mass spectra at $1100^{\circ} \mathrm{C}$ is shown in fig. 2 .

Fig. 3 shows micrographs of the surface of the present silicon (111) wafer taken at the end of the experiment. During an attempt to increase the temperature to more than $1150^{\circ} \mathrm{C}$ a temperature gradient on the sample became visible and finally melting took place at a bright edge. Afterwards the surface at room temperatures showed a foggy pattern from one edge to the other. The foggy pattern was absent near the melted edge. Fig. 3a is a micrograph of a light foggy part and shows small hillocks $\sim 2 \mu \mathrm{m}$ wide. These hillocks grow as the place of inspection is changed to a more foggy part, becomes like an orange skin and many small dints start to overlap (fig. 3b). This "orange skin" disappears as the plane of inspection moves to the part near the melted edge leaving several small dints $\sim 0.5 \mu \mathrm{m}$ wide (fig. $3 \mathrm{c}$ ).

\section{Discussion}

The gradual increases in $\Delta$ and $\psi$ upon heating from 560 up to $870^{\circ} \mathrm{C}$ can be attributed to the removal of surface layers. The gradual increase in $\Delta$ is in accordance with the theory that thin oxide layers covering the surface are removed during heating. However, the gradual increase in $\psi$ cannot be explained on the basis of the theory of a removal of oxide layers. Ellipsometric measurements on silicon (111) and (100) surfaces [6] revealed a decrease of $\psi$ upon adsorption of gases which is opposite in sign to the prediction of a theoretical calculation based on the thin layers on the silicon surface. Therefore the silicon (111) surface measured here is not only composed of simple oxide layers but of a mixture of oxide and adsorbed contamination. In fact, as much as 4 monolayers of carbon contamination are roughly estimated to exist on the sample surface prior to heating. Although the Auger electron spectra measured after heating at $975^{\circ} \mathrm{C}$ showed only a clear silicon 
LMM signal, $\psi$ increases until the temperature reaches $1080^{\circ} \mathrm{C}$, indicating some sort of change on the surface. Mass spectra at $975^{\circ} \mathrm{C}$ showed, in both sample positions, a $\mathrm{H}_{2}^{+}$peak which was as much as 20 times higher than that obtained at room temperature. This may have some relation to the increase in $\psi$.

After heating at $1080^{\circ} \mathrm{C}$ both $\Delta$ and $\psi$ showed drastic decreases. As already mentioned the Auger electron spectra showed no sign of impurities, therefore, the change of the ellipsometric signals cannot be explained by a surface segregation of impurities. $\Delta$ and $\psi$ decreased even to $155.15^{\circ}$ and $9.29^{\circ}$ respectively at the end of mass spectroscopic measurements. Hopper et al. [2] found the same kind of drastic decrease in $\Delta$ with heating at $900^{\circ} \mathrm{C}$ and examination of the surface using a scanning electron microscope showed evidence of severe non-uniform etching. Micrographs of the present sample, also indicate roughened surfaces. Theoretical and experimental studies of the effect of surface roughness on $\Delta$ and $\psi$ have been carried out by many workers [7]. The decreases in $\Delta$ and $\psi$ with increasing surface roughness as indicated in this experiment is in agreement with the trend suggested by these studies. Roughened surfaces of silicon single crystal due to heating are also reported by several workers [8].

Another drastic change during heating at $1080^{\circ} \mathrm{C}$ and higher is an extreme difference in peak height at mass number 28 of mass spectra in different sample positions. Since the peak at mass number 28 is quite sensitive to the sample position, a stream of gases can be expected which originate in the sample surface layer. Therefore gases such as $\mathrm{CO}, \mathrm{N}_{2}$ and $\mathrm{C}_{2} \mathrm{H}_{4}$, which might be present in the surroundings of the sample, are ruled out because these gases are distributed almost uniformly within a few seconds of heating. Since the Auger electron spectra show only a silicon peak and the mass spectra show a drastic change in peak height only at mass number 28 , the most probably cause of this peak is the presence of silicon. The vapour pressure of silicon is reported to be as high as $10^{-5}$ Torr at $1177^{\circ} \mathrm{C}$ [9]. It has also been observed that the vapour pressure of most materials, in the pressure range below 1 Torr, can be represented as a function of $T$ by the relation

$\log P=A-B / T$,

where $A$ and $B$ are constants and equal to $12.72(P$ in $\mu \mathrm{m})$ and $21300 \mathrm{~K}$ for silicon respectively [9]. The rate of sublimation of silicon expressed in the number of atoms per square centimeter per second $(\mu)$, which may be proportional to the peak height at mass number 28 , can also be represented by the relation [9]

$\log \mu=A^{\prime}-B / T$,

where $A^{\prime} \simeq 30$. Fig. 4 shows the extrapolated vapour pressure of silicon and a plot of the relative intensity at mass number 28 (peak height in position (1) - peak height in position (2)), the ordinates of which are adjusted arbitrarily. Below $\sim 900^{\circ} \mathrm{C}$ the vapour pressure of silicon is too low to be measured with the mass spectrometer; therefore the plotting of relative intensity at mass number 28 below $\sim 900^{\circ} \mathrm{C}$ has no real meaning. Above $\sim 900^{\circ} \mathrm{C}$ the plotting of relative intensity fol- 


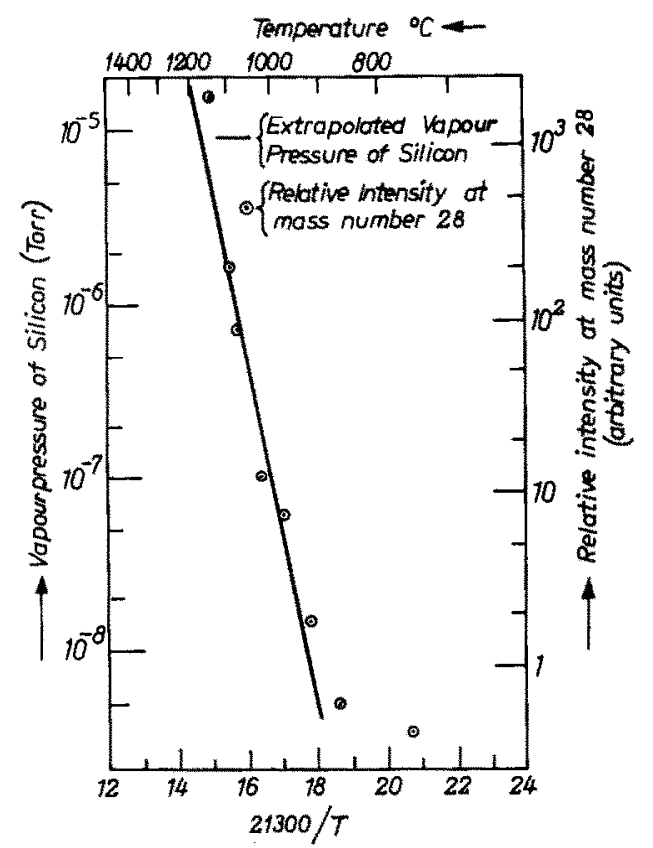

Fig. 4. A comparison of relative intensity at mass number 28 in fig. 2 with the extrapolated vapour pressure of silicon. The ordinate is adjusted arbitrarily.

lows the line of the vapour pressure of silicon. The vapour pressures of silicon at 975 and $1080^{\circ} \mathrm{C}$ are $4.5 \times 10^{-8}$ and $9.5 \times 10^{-7}$ Torr respectively. Since a vapour pressure of $1 \times 10^{-6}$ Torr roughly corresponds to the removal of a monolayer of silicon atoms per second, it is quite plausible that the heating at around $1000^{\circ} \mathrm{C}$ is a critical temperature for producing topographical changes on the surface.

The fact that sublimation causes surface roughness is probably due to the nonuniformity of the sublimation energy over the surface; this depends on the existence of impurities and defects. Alkali and alkaline earth metals have been detected by secondary ion mass spectroscopy on the silicon (111) surface heated at $1000^{\circ} \mathrm{C}$ for $1 \mathrm{~h} \mathrm{[10].} \mathrm{These} \mathrm{impurities} \mathrm{cannot} \mathrm{be} \mathrm{detected} \mathrm{by} \mathrm{Auger} \mathrm{electron} \mathrm{spectroscopy.}$ However, the micrographs and electron micrographs of roughened surfaces taken by several workers [8] differ from each other; even complete smoothness was observed at every heating temperature [11]. This suggests that the surface roughness is quite sensitive to the conditions of surface treatment and heating. Fig. $3 \mathrm{c}$ shows a smooth surface, except for small dints, which is probably caused by the fact that the rate of sublimation is so high that the difference in energy of sublimation over the surface has little effect. This may be the cause of less surface roughness in the case of heating at higher temperature than $1200^{\circ} \mathrm{C}$, which is a usual heating temperature for silicon. 


\section{Acknowledgements}

The authors wish to thank Professor M.I. Sparnaay for his helpful discussions. They are also indebted to Mr. J.C. Lodder for taking the micrographs of the sample surface. The first author (S.K.) has benefited from the Sakkokai Foundation.

\section{References}

[1] M.M. Ibrahim and N.M. Bashara, Surface Sci. 30 (1972) 680 .

[2] M.A. Hopper, R.A. Clarke and L. Young, Surface Sci. 56 (1976) 472.

[3] R.M.A. Azzam and N.M. Bashara, J. Opt. Soc. Am. 61 (1971) 773.

[4] P.W. Palmberg, G.E. Riach, R.E. Weber, N.C. MacDonald, Handbook of Auger Electron Spectroscopy (Physical Electronics Industries, Minnesota, 1972).

[5] C.C. Chang, Surface Sci. 25 (1971) 53.

[6] F. Meyer and G.A. Bootsma, Surface Sci. 16 (1969) 221.

[7] I. Ohlídal, F. Lukeš and K. Navrátil, Surface Sci. 45 (1974) 91; and references therein.

[8] G.L. Russel and D. Haneman, J. Electrochem. Soc. 114 (1967) 398; and references therein.

[9] S. Dushman, Scientific Foundations of Vacuum Technique (Wiley, New York, 1962) p. 691.

[10] S. Storp, Ph.D. Thesis, University of Koln (1974).

[11] B.A. Joyce, J.H. Neave and B.E. Watts, Surface Sci. 15 (1969) 1. 